\title{
Telemetry System for Assessing Jaw-Muscle Function in Free-ranging Primates
}

\author{
Susan H. Williams • Christopher J. Vinyard • \\ Kenneth E. Glander • Max Deffenbaugh • \\ Mark F. Teaford • Cynthia L. Thompson
}

Received: 1 August 2007 / Accepted: 26 September 2007 /

Published online: 3 September 2008

(C) Springer Science + Business Media, LLC 2008

\begin{abstract}
In vivo laboratory-based studies describing jaw-muscle activity and mandibular bone strain during mastication provide the empirical basis for most evolutionary hypotheses linking primate masticatory apparatus form to diet. However, the laboratory data pose a potential problem for testing predictions of these hypotheses because estimates of masticatory function and performance recorded in the laboratory may lack the appropriate ecological context for understanding adaptation and evolution. For example, in laboratory studies researchers elicit rhythmic chewing using foods that may differ significantly from the diets of wild primates. Because the textural and mechanical properties of foods influence jaw-muscle activity and the resulting strains, chewing behaviors studied in the laboratory may not adequately reflect chewing behaviors of primates feeding in their natural habitats. To circumvent this limitation of laboratory-based studies of primate mastication, we developed a system for recording jaw-muscle electromyograms
\end{abstract}

\footnotetext{
S. H. Williams $(\bowtie)$

Department of Biomedical Sciences, Ohio University, Athens, OH 45701, USA

e-mail: willias7@ohio.edu

C. J. Vinyard

Department of Anatomy and Neurobiology, NEOUCOM, Rootstown, OH 44272, USA

K. E. Glander

Department of Biological Anthropology and Anatomy, Duke University, Durham, NC 27708, USA

M. Deffenbaugh

Ohio University, P.O. Box 153, Califon, NJ 07830, USA

M. F. Teaford

Center for Functional Anatomy and Evolution, Johns Hopkins University, Baltimore, MD 21205, USA

C. L. Thompson

Department of Anthropology, Kent State University, Kent, OH 44242, USA
} 
(EMGs) from free-ranging primates so that researchers can conduct studies of primate jaw-muscle function in vivo in the field. We used the system to record jawmuscle EMGs from mantled howlers (Alouatta palliata) at Hacienda La Pacifica, Costa Rica. These are the first EMGs recorded from a noncaptive primate feeding in its natural habitat. Further refinements of the system will allow long-term EMG data collection so that researchers can correlate jaw-muscle function with food mechanical properties and behavioral observations. In addition to furthering understanding of primate feeding biology, our work will foster improved adaptive hypotheses explaining the evolution of primate jaw form.

Keywords Alouatta $\cdot$ electromyography $\cdot$ mastication · telemetry

\section{Introduction}

There is a general consensus among biological anthropologists that the evolution of the primate masticatory apparatus has been strongly influenced by diet. Over 30 years of experimental, laboratory-based research on captive primates has revealed how jaw-muscle activity exerts external forces on the mandible, resulting in internal stresses and strains during chewing and biting (Hylander 1977, 1979b, 1984; Hylander and Johnson 1994; Hylander et al. 1987, 1992, 1998, 2000, 2005). Such studies provide the empirical foundation for comparative studies linking jaw form to masticatory stresses and the mechanical demands of diet or feeding behaviors (Bouvier 1986; Bouvier and Hylander 1981; Daegling 1993, 2001; Hylander 1979a, 1985; Ravosa 1996; Taylor 2002; Vinyard et al. 2003; Williams et al. 2002; Wright 2005). Despite the numerous advances in our understanding of primate feeding gained via experimental research, a major assumption of the studies is that feeding behaviors observed in the laboratory accurately characterize feeding behaviors of conspecific primates in their natural habitats.

In reality, the laboratory setting introduces variables that likely influence feeding and chewing in captive primates, further limiting our ability to test adaptive hypotheses. For example, Thompson et al. (2007) demonstrated that anesthetizing and restraining captive Cebus apella alter their feeding behaviors. After recovery from anesthesia, the restrained individuals chewed significantly slower than when unmanipulated and sitting freely in their cages. Presumably, differences in chewing speed may influence a number of variables associated with the mechanics of mastication, including the rate of force production and power stroke length. In addition, to elicit rhythmic mastication in the laboratory studies, researchers use foods that are not consumed by primates in the wild, including almonds, monkey chow, and hard and soft candies. More importantly, these foods may not adequately represent the range of mechanical and textural properties of wild primate diets (Williams et al. 2005). Because the physical, textural, and mechanical properties of a food influence jaw-muscle activity and bone strain patterns (Agrawal et al. 1998; Foster et al. 2006; Horio and Kawamura 1989; Hylander 1979b, 1984; Hylander and Johnson 1994; Hylander et al. 1998; 2000; Mioche et al. 1999; Møller 1966; Ottenhoff et al. 1996; Woda et al. 2006), the resulting chewing behaviors may not adequately reflect chewing behaviors of primates feeding in their natural habitats. 
This is particularly important because primate foraging strategies are influenced by food mechanical properties, which may account for morphological differences in masticatory form and function between closely-related and sympatric species (Elgart-Berry 2004; Kinzey and Norconk 1990, 1993; Lambert et al. 2004; Overdorff and Strait 1998; Strait 1993; Vinyard et al. 2004; Wright 2005; Yamashita 1998, 2002).

To interpret laboratory-based data on primate mastication in a broader evolutionary adaptive context, researchers must overcome the limitations imposed by the laboratory setting and determine how diets correlate with masticatory function in wild primates. More generally, they need to link masticatory function to selection pressures experienced by primates in the wild. Bock and von Wahlert (1965; Bock 1980) made this general argument about laboratory-based experimental research over 40 years ago, emphasizing that researchers studying the relationship between form and function in an artificial context need to consider the limitations of their data when inferring adaptation. Thus they encouraged researchers to bridge the gap between understanding form-function complexes observed in the laboratory and their biological role, or how they are used in the natural environment throughout the life history of the organism. Given the long and productive history of laboratorybased studies of primate mastication, the appropriate next step is to bridge the gap and link experimental and ecological research programs.

There are 2 potential ways to address the limitations of the in vivo experimental approach to studying primate mastication. A first step would be to provide captive primates with the same foods consumed by conspecifics in the wild or with foods that have similar mechanical properties. Though experimentalists typically do not have access to the exact foods that primates consume in the wild, the mechanical properties for many of the foods consumed by wild conspecifics of captive primate are known (Lambert et al. 2004; Teaford et al. 2006; Wright 2005; Yamashita 1998). However, there has been little effort to ensure that experimental foods match those mechanical properties (Williams et al. 2005). Moreover, one still needs to account for the potential confounding effects of the experimental setting and procedures on primate mastication.

An alternative approach is to bring the laboratory apparatus to the field and record in vivo data from primates feeding in their natural habitats. Until recently, this has not been logistically possible for studies of primate mastication. Researchers cannot use hard-wired electromyographic (EMG) systems that they use in the laboratory in the field because they require an AC power supply, they tether the subject to the system via connective cabling, and they are not portable. There are several batterypowered off-the-shelf EMG systems available which transmit the amplified EMG signal to a remote receiver using radio waves. However, these systems have a number of features that make them unsuitable for field use on free-ranging nonhuman primates: 1) Because they are designed for humans in clinical studies, many of the systems are too heavy for most primates to carry. 2) They are not sufficiently water-tight or rugged to withstand primate habitats. 3) Most systems are too expensive, ranging between $\$ 14,000$ and $\$ 25,000$, to risk damaging in the field. Unfortunately, more affordable systems do not adequately replicate EMG signals for quantitative analysis. Instead, they simply provide a signal indicating whether a muscle is active or not, which is primarily useful for monitoring mortality in free- 
ranging animals. Finally, all EMG telemetry systems have lower sampling rates than hard-wired EMG systems. Hard-wired systems can easily sample EMGs at $10,000 \mathrm{~Hz}$ per channel and can theoretically have an unlimited number of channels. For telemetered EMG, maximum sampling rate and the number of channels is dependent on the amount of bandwidth available for data transmission, the frequency components of the raw EMG signal, and the need to replicate the raw EMG signal accurately with sufficient resolution to allow quantification.

Because of the lack of suitable EMG telemetry devices and the need for more ecologically-relevant studies of primate mastication, we recently designed, developed, and tested a prototype of an EMG telemetry system to use on free-ranging primates. The goal was to design a relatively inexpensive EMG telemetry system that allows us to integrate laboratory-based methods for studying primate mastication with field studies on primate feeding ecology. In addition to allowing researchers to collect more naturalistic EMG data from primates during chewing, one may use the system to collect data from species that cannot be obtained for laboratory studies. Expanding the EMG sample to include a broader taxonomic and morphological range of species can further increase our understanding of jaw-muscle function in primates.

We tested the telemetry system on mantled howlers (Alouatta palliata) at Hacienda La Pacifica in Costa Rica to demonstrate the feasibility of acquiring EMGs from the jaw muscles of wild primates feeding in their natural habitats. Though our ultimate goal is to determine how jaw-muscle activity varies with food mechanical properties in wild primates, we restrict our discussion to the telemetry system and provide data to demonstrate the feasibility of bridging the gap between laboratory and field approaches in studies of primate mastication.

\section{The EMG Telemetry System}

The telemetry system consists of 3 main components: 1) an EMG unit that acquires, amplifies, and transmits the EMG signal; 2) a standard FM radio receiver (Kaito Model KA1103); and 3) a digital compact flash recorder (Marantz Model PMD660). Whereas we purchased the FM radio receiver and digital recorder from vendors, we designed and constructed the EMG unit especially for this project. The EMG unit weighs $88 \mathrm{~g}$ and measures $2.5 \times 4.0 \times 6.5 \mathrm{~cm}$ (Fig. 1). It has inputs for 8 bipolar EMG electrodes, 4 ground wires, a battery charger, and an antenna. The transmitter circuit requires $100 \mathrm{~mW}$ of electrical power that is supplied by 2 rechargeable polymer lithium-ion batteries. The batteries provide $c a .33 \mathrm{~h}$ of continuous transmission. The unit is encased in a waterproof and rigid epoxy compound for protection.

The circuitry for the telemetry unit consists of a low-noise differential amplifier for each bipolar electrode, 2 4:1 multiplexers, and a stereo FM transmitter integrated circuit that accepts the multiplexed EMG data streams at its right and left inputs (Fig. 2). We sampled each EMG channel at 1600 samples per second. Each multiplexer samples and rapidly switches among 4 EMG channels that are combined, i.e., multiplexed, into a single data stream. Via multiplexing, the system can transmit all 8 EMG channels through the left and right stereo channels of a standard FM stereo radio transmission. An FM stereo transmission permits $30 \mathrm{kHz}$ 


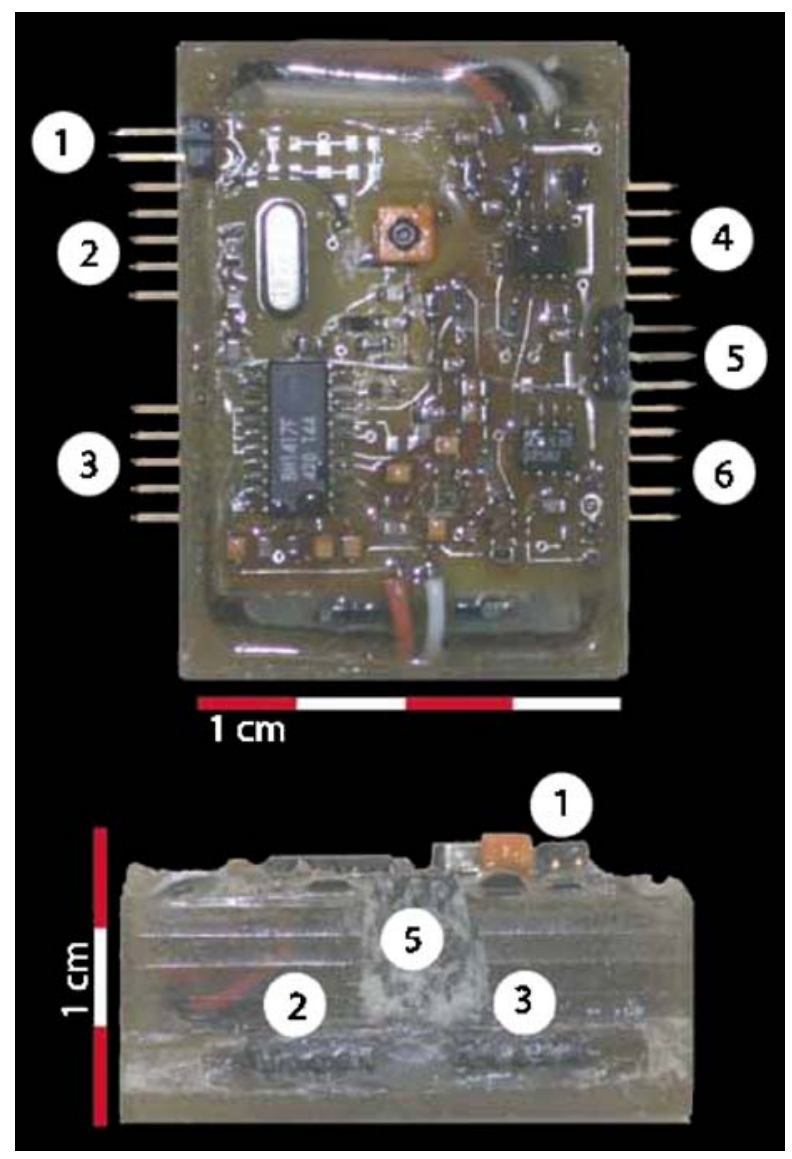

Fig. 1 Superior (top) and right lateral (bottom) views of the telemetry system used to collect jaw-muscle EMGs from wild mantled howlers. Contact pins are numbered as follows: 1, antenna; 2, 3, 4, 6, banks of electrodes and ground pins; 5 , battery charger. The antenna requires 1 pin only; the lower pin is to stabilize the connection with the antenna plug. The 5 contact pins in 2-6 are placed in the following order: 1 bipolar electrode ( 2 pins), ground pin (1 pin), 1 bipolar electrode ( 2 pins). The battery charger is connected to 2 pins at a time to charge each battery. The center pin is shared between batteries and connects to the negative $(-)$ lead of the first battery and the positive $(+)$ lead of the second battery.

of total audio bandwidth, which should have afforded $3.75 \mathrm{kHz}$ of signal bandwidth for each of the 8 electrodes. However the practical limitations of off-the-shelf transmitter and receiver components and the need for a simple method of demultiplexing the received data limited us to $800 \mathrm{~Hz}$ of signal bandwidth (1600 samples per second) per electrode in this first version of the system.

The multiplexed data streams are transmitted as a continuous signal up to $50 \mathrm{~m}$ on a selectable station within the $88-108 \mathrm{MHz}$ commercial FM radio band. The range of transmitters is limited by FCC Part 15, which regulates the transmitted power level in this frequency band. The FM stereo radio receiver receives the data streams and reproduces the left and right multiplexed EMG data streams as its stereo output. 


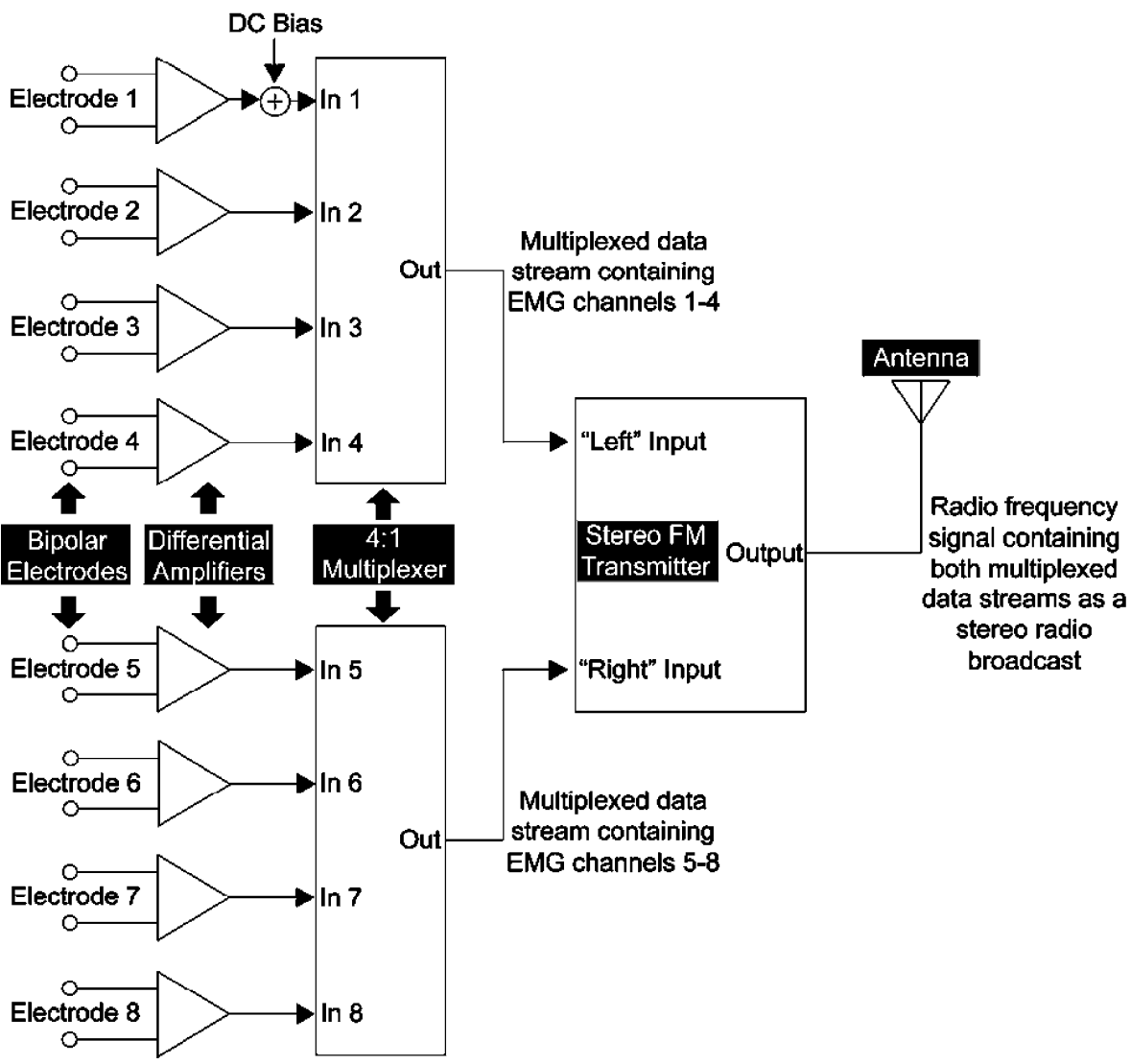

Fig. 2 Block diagram of the circuitry for the EMG telemetry unit. Block arrows identify specific labeled components of the circuitry only.

We record the data streams at a $44.1-\mathrm{kHz}$ sampling rate using the stereo microphone input of the digital recorder. After we completed data collection, we downloaded the multiplexed EMG data streams from the digital recorder in the form of a .wav file to a laptop computer.

The transmitter applies a small DC bias to EMG channel 1. The DC bias is simply a constant voltage offset to channel 1 relative to the other channels that allows us to reconstruct the recorded multiplexed data streams. A custom-written program in Matlab 7.0 uses the DC bias to synchronize and reconstruct the 8 individual EMG records from the multiplexed data streams. The DC bias on channel 1 produces an audible high-pitched $(1600 \mathrm{~Hz})$ sound on the multiplexed signal from the FM receiver. This allows the transmitter itself to function as a radiotracking device.

Bipolar electrodes that acquire the EMG interference patterns are constructed from nylon insulated nickel-chromium alloy wire (California Fine Wire Co.). One end of each electrode wire is soldered to a contact pin and attached to the electrode inputs on the unit. We removed $c a .1 \mathrm{~mm}$ of insulation from the tip of the opposite end of the electrode wire for implantation into the muscle. The antenna is 
constructed from stainless steel wire. We used a needle electrode (Grass Model E2) as the ground wire.

The telemetry system cost $<\$ 1500$ to build, $\$ 200$ of which was for the components needed to build the telemetry unit. The remaining costs were associated with the FM receiver, compact flash recorder, compact flash cards, battery charger (Hobbico Accu-Cycle ProSeries Elite), and other expendable materials.

\section{Methods}

\section{Field Testing}

We tested the EMG telemetry system during a 2 week field season at Hacienda La Pacifica, Costa Rica. We successfully recorded EMGs from 2 male howlers, 1 adult age $c a .9 \mathrm{yr}$ (subject 1) and 1 juvenile, age $c a$. $3.5 \mathrm{yr}$ (subject 2). We attempted to record EMGs from 2 additional individuals, both female. However, the attempts were unsuccessful due to weather-related and technical issues (subject 3) and limited field time for observation (subject 4). Therefore, we restrict all further discussion of implantation methods and results to subjects 1 and 2 .

Per procedures outlined by Glander et al. (1991), we darted and captured individuals via a $\mathrm{CO}_{2}$-powered gun that delivers a nonbarbed dart (Pneu-Dart ${ }^{\circledR}$ ) loaded with Telazol ${ }^{\circledR}$ (Fort Dodge) at a dosage of $25 \mathrm{mg} / \mathrm{kg}$. Once we caught the subjects, we transported them back to the research facility for electrode implantation. We maintained immobilization with additional doses of Telazol IM (3-5 mg/kg) as needed. We administered Lutoprofen ${ }^{\circledR}(2 \mathrm{mg} / \mathrm{kg}$ IM every $24 \mathrm{~h})$ as an analgesic.

In subject 1, we placed electrodes in the left and right superficial masseter, deep masseter, anterior temporalis, and posterior temporalis muscles. In subject 2, we placed 2 electrodes in the left and right superficial and deep masseter muscles. To insert the electrodes, we shaved the skin overlying the masseter and temporalis muscles and along the midline of the back just caudal to the scapulae. We then cleaned the areas with Betadine scrubs. We made small vertical incisions $(c a .1 \mathrm{~cm})$ in the skin overlying the masseter or the temporalis muscles on each side. We inserted the exposed tips of each sterilized electrode into a sterile 30-gauge hypodermic needle and bent the electrode wire back to lie parallel to the shaft of the needle, creating small hooks in the wires. For each electrode, we inserted the needle containing the exposed electrode tip into the target muscle through the incision until the tip of the needle contacted bone. We then held the wires in place and removed the needle, leaving the electrode in the muscle.

After electrode placement, we passed a sterile trocar subcutaneously from a small incision between the shoulder blades to each incision overlying the jaw muscles. We inserted the free ends of the electrodes and their attached contact pins into the opening of the trocar. We then removed the trocar, pulling the electrodes through the incision between the shoulder blades. We attached the free ends of the electrodes to the transmitter at the appropriate contact pins via a small plastic connector. Once all electrodes were in place, we closed the incisions overlying the jaw muscles and between the shoulder blades via a continuous subcuticular suture technique and absorbable suture (Ethicon J397H). 
We inserted the needle-end of the ground wire subcutaneously under the skin of the back and sutured it in place. We connected the opposite end to the appropriate contact pin on the telemetry unit. We then wrapped the entire transmitter in elastic medical tape for additional protection and attached it to the back of the subject with self-adhesive veterinary or elastic tape. Once the transmitter was securely in place, we placed the subject in a vest especially designed for primates (Lomir Biomedical) for further protection of the transmitter (Fig. 5). As in previous field studies involving capture and release at Hacienda La Pacifica, we allowed the subject to recuperate overnight in a burlap bag.

We released both subjects between 0800 and $0830 \mathrm{~h}$ the morning after implantation in the location where we captured them. We followed them during the day for 2 days to record EMG data and feeding behaviors. Once the battery on the telemetry system ran out, or we recorded sufficient data, we recaptured the subjects and transported them back to the research facility to remove the electrodes and telemetry system. During the process, we removed all electrodes, cleaned all incisions, and used a continuous subcuticular suture to close the incisions on the subject's face and back. We then placed the immobilized subjects in burlap bags until they were alert enough to release at the recapture site the following morning.

\section{Results}

On release with the telemetry system, both individuals immediately climbed a nearby tree. We did not observe subject 1 feed on the day of release. We relocated him the following day and recorded EMGs from a distance of $c a .25 \mathrm{~m}$ while he fed extensively on young leaves of Astronium. Unfortunately, the battery died and transmission ceased during feeding. We recaptured him to retrieve the telemetry system when he resumed resting.

Subject 2 immediately moved to a food tree on release and in $\leq 2 \mathrm{~h}$ consumed several mouthfuls of leaves from a vine of the family Combrataceae (Fig. 3). Over the next $2 \mathrm{~h}$ he rested, and we were able to record EMGs during multiple bouts of tooth grinding (Fig. 4). We recorded EMGs during numerous additional feeding bouts on berries and leaves throughout the morning and early afternoon. The following morning, we relocated subject 2 in the same general area and recorded additional feeding bouts on berries and leaves over $7 \mathrm{~h}$. We recorded EMGs from $>400$ chews, mostly at $\leq 20 \mathrm{~m}$. Once we collected sufficient data, we captured him to retrieve the transmitter.

In addition to recording EMGs and feeding behaviors, we also observed the subjects to gauge the effects of the implantation procedure and the presence of the telemetry unit and vest on their behavior. Recuperation from the implantation procedure was uneventful for both subjects, and neither one exhibited obvious side effects associated with the implantation procedure. Moreover, the telemetry system, electrodes, and vest did not appear to limit locomotion, postural or feeding behaviors (Fig. 5), and other individuals did not react negatively to the subjects wearing the vest. Finally, we observed subject 2 opportunistically several days later in the canopy and he appeared to be in good condition. 


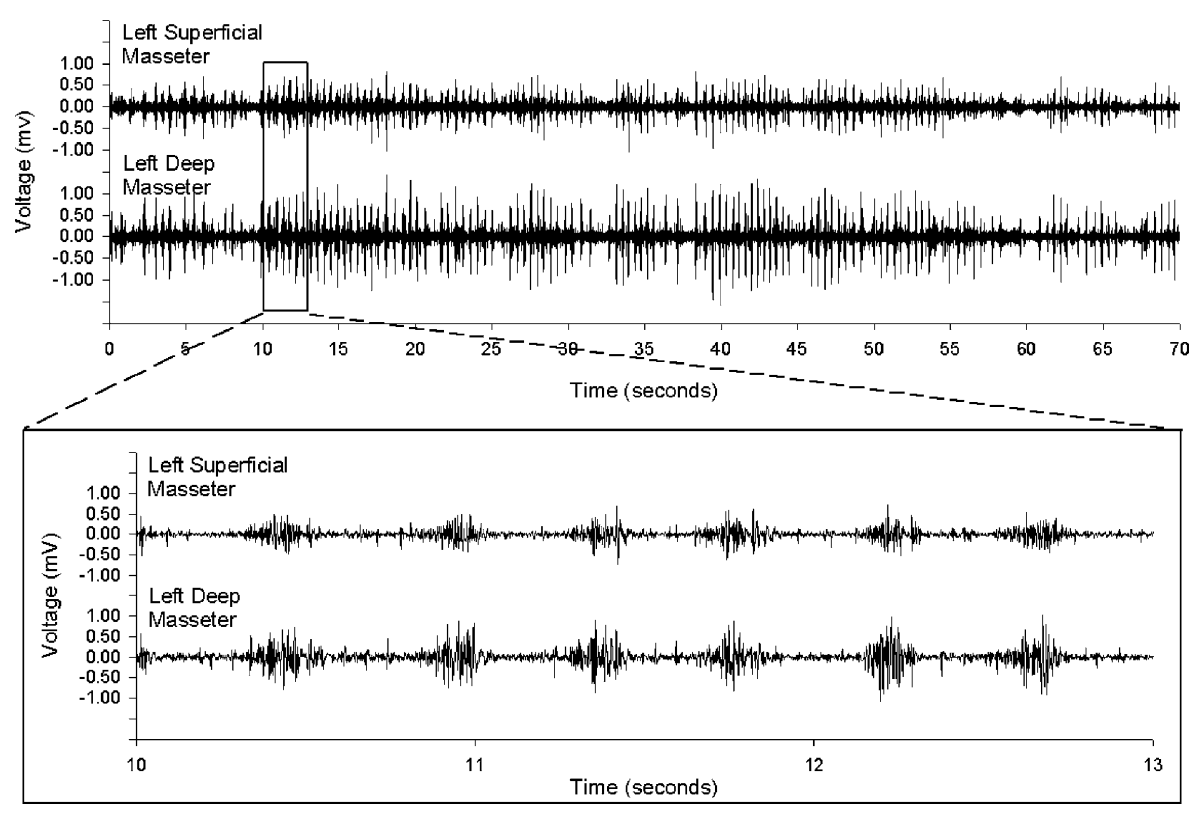

Fig. 3 Examples of raw EMGs from subject 2 during the mastication of leaves. The top sequences shows $70 \mathrm{~s}$ of EMG from a chewing sequence that lasted about $160 \mathrm{~s}$. The bottom sequence shows the raw EMGs for a 3 -s segment of this sequence. We show only 2 electrodes for clarity.

\section{Discussion}

We demonstrated the feasibility of acquiring EMG data from free-ranging primates. During a relatively short field season, we tested the prototype and recorded the first EMGs from primates feeding in their natural habitat. This technology represents a major contribution to the tools available for studying primate mastication and potentially other behaviors, e.g., locomotion. Our study is one of the first to integrate laboratory-based in vivo techniques for understanding the dynamics of primate mastication and biting with fieldwork on primate feeding ecology (Vinyard et al. 2004, in press; Yamashita et al. 2004).

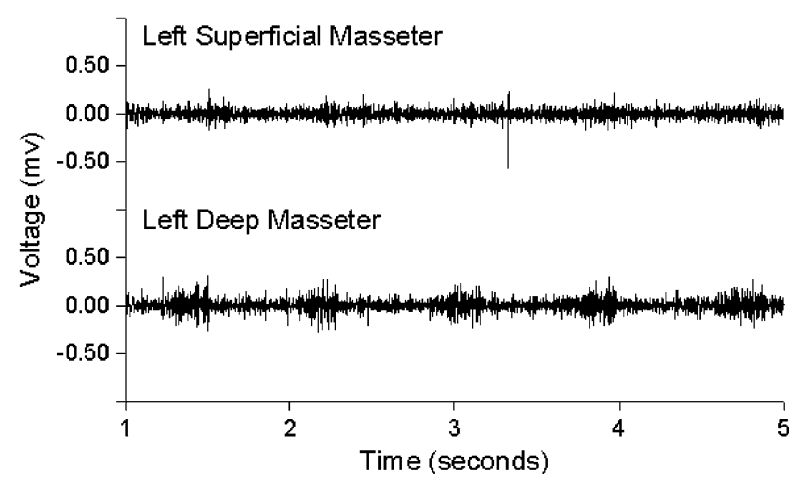

Fig. 4 Raw EMGs from subject 2 during tooth grinding. 

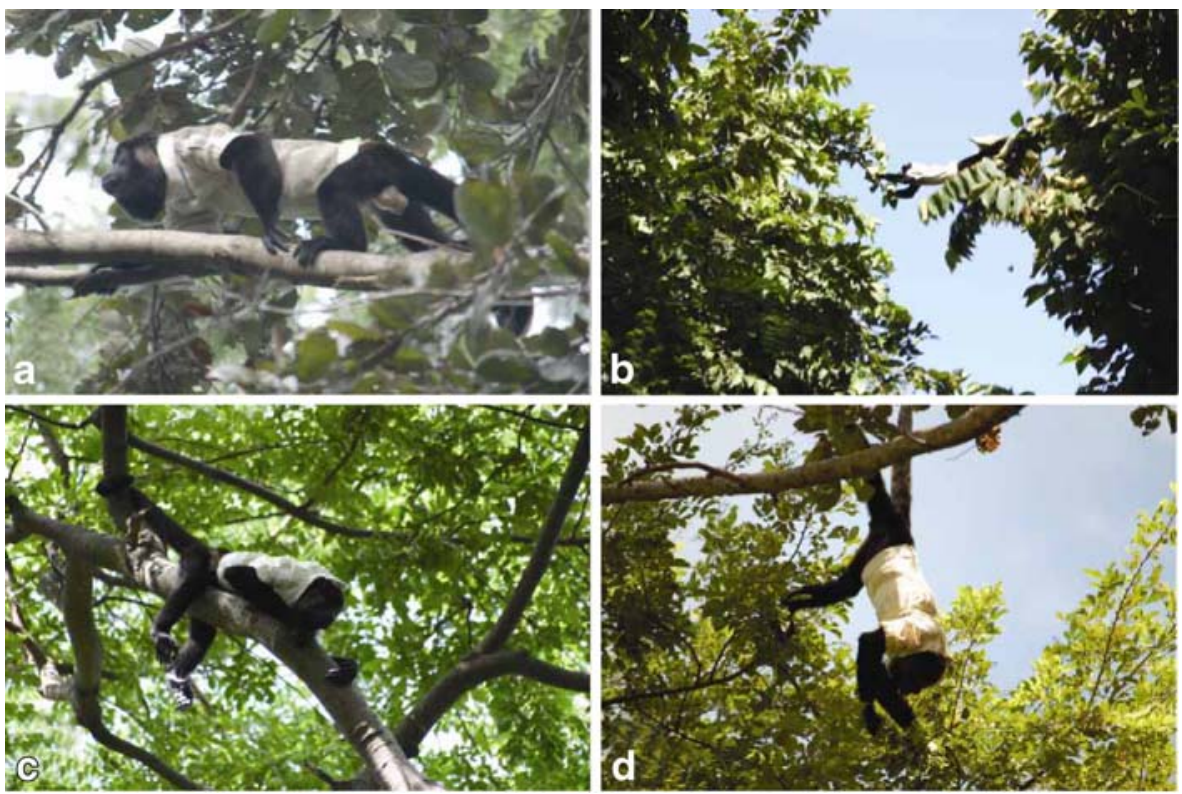

Fig. 5 Subject 1 (a, b) and subject 2 (c, d) wearing the telemetry unit and protective vest. Subjects exhibited all of their normal locomotor, postural, and feeding behaviors while they were wearing the unit and vest.

Though our pilot study was successful, we encountered several technological challenges that limited the amount of data that we collected during the field season. First, we expected that continuous transmission over a 33-h period afforded by the batteries would provide sufficient data on each individual. However, given that 1 of the 2 individuals did not eat the entire first day of recording and for part of the second day, we need to collect data over a much longer period. Because batteries are the heaviest and largest component of the telemetry unit, more powerful batteries, which are typically larger, are not a viable option. One potential solution is to prolong battery life by modifying the circuitry to include a microcontroller that deactivates radio transmission when there is no EMG activity of significant amplitude. When the subject begins to feed or to engage in other behaviors resulting in an EMG signal, the system is activated and the EMG data streams are transmitted. We estimate that the change to the circuitry will conserve battery life sufficiently to allow us to record EMG activity for up to 1 week per individual.

Increasing transmission duration has other logistical and scientific benefits. Foremost, it allows us to collect substantially more EMG data with a single implantation procedure, reducing the risk of injury to the subject because of repeated captures. In addition, increased transmission duration will allow us to record jawmuscle EMGs during the mastication of a potentially broader range of foods that will likely occur over the week-long period. Because one of our primary goals is to understand how jaw-muscle behavior changes with mechanical properties of food in a wild primate, sampling EMGs during the mastication of as many foods as possible during a single experiment is paramount. Finally, by recording EMGs over a longer period, we will be able to assess the effects of anesthesia and handling on chewing 
rate and other variables that may influence the EMG data. Coupled with behavioral observations before darting and captures, we will be able to select the EMG data associated with the chewing behaviors that may be more representative of a freeranging primate. Moreover, foods eaten later may also be more representative of actual dietary composition simply because the subjects may consume the first foods encountered on release given that they will not have eaten for approximately $24 \mathrm{~h}$.

Though we are optimistic about expanding the research beyond mantled howlers at Hacienda La Pacifica, we recognize that the technology is not suitable for use on all primate species. Researchers wishing to conduct similar studies must consider their choice of species carefully. In addition to considering risks related to darting and capturing primates, the telemetry system itself poses some limitations on which species are suitable subjects. Whereas the mantled howlers exhibited no difficulty with locomotion or assuming normal postural behaviors, the physical dimensions of the current unit may simply be too large to allow smaller subjects to move freely once it is attached. In contrast, the weight of the telemetry unit is probably a negligible load for mantled howlers and even smaller primates to carry. Male and female mantled howlers weigh $c a .5790 \mathrm{~g}$ and $4726 \mathrm{~g}$, respectively (Glander 2006). Thus, at $88 \mathrm{~g}$, the telemetry unit is only $1.4 \%$ the body mass of males and $1.9 \%$ the body mass of females. Considering that females carry their infants for $\leq 4-5 \mathrm{mo}$, at which time they can weigh $600-850 \mathrm{~g}$ (Glander et al. 1991), or $\leq 18 \%$ of their body mass, the added weight of the telemetry unit is negligible. Gursky (1998) provided empirical evidence showing that tarsiers can carry radiocollars weighing as much as $7.6 \%$ of their body mass with no apparent negative effects on their behavior. Thus, the added mass of the telemetry system we used probably would be negligible for primates weighing $\leq 1150 \mathrm{~g}$ and likely interfere little with their behavior or physiology. Taking this into consideration, in addition to modifying the circuitry to increase battery life, we will also investigate ways to miniaturize the entire unit further to broaden the range of species that researchers can study.

Finally, it is important to note that the mantled howlers at Hacienda La Pacifica are ideal for this type of study for reasons beyond their body size. First, darting and anesthesia protocols for mantled howlers are reliable. Second, because the canopy at Hacienda La Pacifica is low, with almost all of the trees $<20 \mathrm{~m}$, and because mantled howlers are diurnal, darting and capture are relatively easy. This also facilitates observation and following subjects to collect behavioral data as they feed. Third, the low canopy coupled with the flat terrain of Hacienda La Pacifica benefits signal transmission and reception. Finally, mantled howlers are relatively sedentary and do very little social grooming, reducing the likelihood that sutures or electrode wires will be pulled out. We considered all of these factors in our selection of the species for the pilot study, and they were undoubtedly integral to our successful recording of jaw-muscle EMGs in a wild free-ranging primate on the first attempt.

Acknowledgments We thank Randy Ford and Margaret Clarke for assistance in the field and Stephan Schmidheiny and the Board of Directors of Hacienda La Pacifica for their permission to work on Hacienda La Pacifica and for their continued support and help. We also like to thank Drs. Nancy Stevens and Kristian Carlson for the invitation to contribute to this issue. The National Science Foundation (BCS0507074, DBC-9118876, and SBR-9601766) and the Ohio University Research Committee supported our research. 


\section{References}

Agrawal, K. R., Lucas, P. W., Bruce, I. C., \& Prinz, J. F. (1998). Food properties that influence neuromuscular activity during human mastication. Journal of Dental Research, 77, 1931-1938.

Bock, W. J. (1980). The definition and recognition of biological adaptation. American Zoologist, 20, $217-227$.

Bock, W. J., \& von Wahlert, G. (1965). Adaptation and the form-function complex. Evolution; International Journal of Organic Evolution, 19, 269-299. doi:10.2307/2406439.

Bouvier, M. (1986). A biomechanical analysis of mandibular scaling in Old World monkeys. American Journal of Physical Anthropology, 69, 473-482. doi:10.1002/ajpa.1330690406.

Bouvier, M., \& Hylander, W. L. (1981). Effect of bone strain on cortical bone structure in macaques (Macaca mulatta). Journal of Morphology, 167, 1-12. doi:10.1002/jmor.1051670102.

Daegling, D. J. (1993). The relationship of in vivo bone strain to mandibular corpus morphology in Macaca fascicularis. Journal of Human Evolution, 25, 247-269. doi:10.1006/jhev.1993.1048.

Daegling, D. J. (2001). Biomechanical scaling of the hominoid mandibular symphysis. Journal of Morphology, 250, 12-23. doi:10.1002/jmor.1055.

Elgart-Berry, A. (2004). Fracture toughness of mountain gorilla (Gorilla gorilla beringei) food plants. American Journal of Primatology, 62, 275-285. doi:10.1002/ajp.20021.

Foster, K. D., Woda, A., \& Peyron, M. A. (2006). Effect of texture of plastic and elastic model foods on the parameters of mastication. Journal of Neurophysiology, 95, 3469-3479. doi:10.1152/jn.01003.2005.

Glander, K. E. (2006). Average body weight for mantled howling monkeys (Alouatta pallilata): An assessment of average values and variability. In A. Estrada, P. A. Garber, M. Pavelka, \& L. Luecke (Eds.), New perspectives in the study of Mesoamerican primates (pp. 247-263). New York: Springer.

Glander, K. E., Fedigan, L. M., Fedigan, L., \& Chapman, C. (1991). Field methods for capture and measurement of three monkey species in Costa Rica. Folia Primatologica, 57, 70-82.

Gursky, S. (1998). Effects of radio transmitter weight on a small nocturnal primate. American Journal of Primatology, 46, 145-155. doi:10.1002/(SICI)1098-2345(1998)46:2<145::AID-AJP4>3.0.CO;2-W.

Horio, T., \& Kawamura, Y. (1989). Effects of texture of food on chewing patterns in the human subject. Journal of Oral Rehabilitation, 16, 177-183. doi:10.1111/j.1365-2842.1989.tb01331.x.

Hylander, W. L. (1977). In vivo bone strain in the mandible of Galago crassicaudatus. American Journal of Physical Anthropology, 46, 309-326. doi:10.1002/ajpa.1330460212.

Hylander, W. L. (1979a). Functional significance of primate mandibular form. Journal of Morphology, 160, 223-240. doi:10.1002/jmor.1051600208.

Hylander, W. L. (1979b). Mandibular function in Galago crassicaudatus and Macaca fascicularis: an in vivo approach to stress analysis of the mandible. Journal of Morphology, 159, 253-296. doi:10.1002/ jmor. 1051590208 .

Hylander, W. L. (1984). Stress and strain in the mandibular symphysis of primates: a test of competing hypotheses. American Journal of Physical Anthropology, 64, 1-46. doi:10.1002/ajpa.1330640102.

Hylander, W. L. (1985). Mandibular function and biomechanical stress and scaling. American Zoologist, $25,315-330$.

Hylander, W. L., \& Johnson, K. R. (1994). Jaw muscle function and wishboning of the mandible during mastication in macaques and baboons. American Journal of Physical Anthropology, 94, 523-547. doi:10.1002/ajpa.1330940407.

Hylander, W. L., Johnson, K. R., \& Crompton, A. W. (1987). Loading patterns and jaw movements during mastication in Macaca fascicularis: a bone-strain, electromyographic, and cineradiographic analysis. American Journal of Physical Anthropology, 72, 287-314. doi:10.1002/ajpa.1330720304.

Hylander, W. L., Johnson, K. R., \& Crompton, A. W. (1992). Muscle force recruitment and biomechanical modeling: an analysis of masseter muscle function during mastication in Macaca fascicularis. American Journal of Physical Anthropology, 88, 365-387. doi:10.1002/ajpa.1330880309.

Hylander, W. L., Ravosa, M. J., Ross, C. F., \& Johnson, K. R. (1998). Mandibular corpus strain in primates: further evidence for a functional link between symphyseal fusion and jaw-adductor muscle force. American Journal of Physical Anthropology, 107, 257-271. doi:10.1002/(SICI)1096-8644 (199811) 107:3<257::AID-AJPA3>3.0.CO;2-6.

Hylander, W. L., Ravosa, M. J., Ross, C. F., Wall, C. E., \& Johnson, K. R. (2000). Symphyseal fusion and jaw-adductor muscle force: an EMG study. American Journal of Physical Anthropology, 112, 469492. doi:10.1002/1096-8644(200008)112:4<469::AID-AJPA5>3.0.CO;2-V.

Hylander, W. L., Wall, C. E., Vinyard, C. J., Ross, C., Ravosa, M. R., Williams, S. H., et al. (2005). Temporalis function in anthropoids and strepsirrhines: an EMG study. American Journal of Physical Anthropology, 128, 35-56. doi:10.1002/ajpa.20058. 
Kinzey, W. G., \& Norconk, M. A. (1990). Hardness as a basis of fruit choice in two sympatric primates. American Journal of Physical Anthropology, 81, 5-15. doi:10.1002/ajpa.1330810103.

Kinzey, W. G., \& Norconk, M. A. (1993). Physical and chemical properties of fruits and seeds eaten by Pithecia and Chiropotes in Surinam and Venezuela. International Journal of Primatology, 14, 207226. doi:10.1007/BF02192632.

Lambert, J. E., Chapman, C. A., Wrangham, R. W., \& Conklin-Brittain, N. L. (2004). Hardness of cercopithecine foods: implications for the critical function of enamel thickness in exploiting fallback foods. American Journal of Physical Anthropology, 125, 363-368. doi:10.1002/ajpa.10403.

Mioche, L., Bourdiol, P., Martin, J. F., \& Noel, Y. (1999). Variations in human masseter and temporalis muscle activity related to food texture during free and side-imposed mastication. Archives of Oral Biology, 44, 1005-1012. doi:10.1016/S0003-9969(99)00103-X.

Møller, E. (1966). The chewing apparatus. Acta Physiologica Scandinavica, 69, 9-212.

Ottenhoff, F. A., van der Bilt, A., van der Glas, H. W., Bosman, F., \& Abbink, J. H. (1996). The relationship between jaw elevator muscle surface electromyogram and simulated food resistance during dynamic condition in humans. Journal of Oral Rehabilitation, 23, 270-279. doi:10.1111/ j.1365-2842.1996.tb00852.x.

Overdorff, D. J., \& Strait, S. G. (1998). Seed handling by three prosimian primates in southeastern Madagascar: implications for seed dispersal. American Journal of Primatology, 45, 69-82. doi:10.1002/(SICI)1098-2345(1998)45:1<69::AID-AJP6>3.0.CO;2-U.

Ravosa, M. J. (1996). Jaw morphology and function in living and fossil Old World monkeys. International Journal of Primatology, 17, 909-932. doi:10.1007/BF02735294.

Strait, S. G. (1993). Differences in occlusal morphology and molar size in frugivores and faunivores. Journal of Human Evolution, 25, 471-484. doi:10.1006/jhev.1993.1062.

Taylor, A. B. (2002). Masticatory form and function in the African apes. American Journal of Physical Anthropology, 117, 133-156. doi:10.1002/ajpa.10013.

Teaford, M. F., Lucas, P. W., Ungar, P. S., \& Glander, K. E. (2006). Mechanical defenses in leaves eaten by Costa Rican howling monkeys (Alouatta palliata). American Journal of Physical Anthropology, 129, 99-104. doi:10.1002/ajpa.20225.

Thompson, C., Jackson, E., Stimpson, C., \& Vinyard, C. (2007). Assessing how experimental and surgical manipulations during in vivo laboratory research influence chewing speed in tufted capuchins (Cebus apella). American Journal of Physical Anthropology, (Supplement 44), 231.

Vinyard, C. J., Wall, C. E., Williams, S. H., \& Hylander, W. L. (2003). Comparative functional analysis of skull morphology of tree-gouging primates. American Journal of Physical Anthropology, 120, 153170. doi:10.1002/ajpa.10129.

Vinyard, C. J., Yamashita, N., \& Tan, C. (2004). Maximum bite forces among three sympatric Hapalemur species at Ranomafana National Park, Madagascar. Journal of Morphology, 260, 338.

Vinyard, C. J., Yamashita, N., \& Tan, C. Linking laboratory and field approaches in studying the evolutionary physiology of biting in bamboo lemurs. International Journal of Primatology, in press.

Williams, S. H., Wall, C. E., Vinyard, C. J., \& Hylander, W. L. (2002). A biomechanical analysis of skull form in gum-harvesting galagids. Folia Primatologica, 73, 197-209. doi:10.1159/000065429.

Williams, S., Wright, B., Truong, V., Daubert, C., \& Vinyard, C. (2005). Mechanical properties of foods used in experimental studies of primate masticatory function. American Journal of Primatology, 67, 329-346. doi:10.1002/ajp.20189.

Woda, A., Foster, K., Mishellany, A., \& Peyron, M. A. (2006). Adaptation of healthy mastication to factors pertaining to the individual or to the food. Physiology \& Behavior, 89, 28-35. doi:10.1016/j. physbeh.2006.02.013.

Wright, B. W. (2005). Craniodental biomechanics and dietary toughness in the genus Cebus. Journal of Human Evolution, 48, 473-492. doi:10.1016/j.jhevol.2005.01.006.

Yamashita, N. (1998). Functional dental correlates of food properties in five Malagasy lemur species. American Journal of Physical Anthropology, 106, 169-188. doi:10.1002/(SICI)1096-8644(199806) 106:2<169::AID-AJPA5>3.0.CO;2-L.

Yamashita, N. (2002). Diets of two lemur species in different microhabitats in Beza Mahafaly Special Reserve, Madagascar. International Journal of Primatology, 23, 1025-1051. doi:10.1023/ A:1019645931827.

Yamashita, N., Vinyard, C., \& Tan, C. (2004). Food properties and jaw performance in three sympatric species of Hapalemur in Ranomafana National Park, Madagascar. American Journal of Physical Anthropology, (Supplement 38), 213. 